\title{
Practical Investigations of the Method for Indirect Control of Acoustic Load Parameters
}

\author{
V.N. Khmelev \\ Biysk Technological Institute (branch) of Altay State Technical University after I.I. Polzunov, \\ 659328 Biysk, Altay Region, PO box 416, Russia
}

Tel: 8-385-443-2570 E-mail: vnh@bti.secna.ru

R.V. Barsukov (Corresponding author)

Biysk Technological Institute (branch) of Altay State Technical University after I.I. Polzunov, 659328 Biysk, Altay Region, PO box 416, Russia

Tel: 8-385-443-2570 E-mail: roman@bti.secna.ru

D.V. Genne

Biysk Technological Institute (branch) of Altay State Technical University after I.I. Polzunov, 659328 Biysk, Altay Region, PO box 416, Russia

Tel: 8-385-443-2570 E-mail: gdv@bti.secna.ru

D.S. Abramenko

Biysk Technological Institute (branch) of Altay State Technical University after I.I. Polzunov, 659328 Biysk, Altay Region, PO box 416, Russia

Tel: 8-385-443-2570Ｅ-mail: ades@bti.secna.ru

E.V. Ilchenko

Biysk Technological Institute (branch) of Altay State Technical University after I.I. Polzunov 659328 Biysk, Altay Region, PO box 416, Russia

Tel: 8-385-443-2570 E-mail: umput90@mail.ru

Received: July 20, 2011 Accepted: August 12, $2011 \quad$ Published: November 1, 2011

doi:10.5539/apr.v3n2p224

URL: http://dx.doi.org/10.5539/apr.v3n2p224

\begin{abstract}
Article is devoted approbation of a method of indirect control of parameters of acoustic loading. Results of measurement of parameters of acoustic loading are presented.

Keywords: Ultrasound,Ultrasonic generators, Acoustic load, Control

\section{Introduction}

Modern ultrasonic electronic generators are the devices transforming the energy of the electric line into the energy of the electric vibrations of the ultrasonic frequency providing the performance of additional functions providing optimum mode of energy transfer into processed media. In order to create universal ultrasonic generators, which are able to provide maximum effective influence on the different technological media in the automatic mode it is necessary to obtain uninterruptedly information on the physical properties of processed media and use this information for the control of the generator and providing of optimum mode of operation.
\end{abstract}


The efficiency of entering of ultrasonic vibrations into the processed medium is provided by the optimum matching of the elements of the system «the generator - the ultrasonic vibrating system - the processed medium».

The matching in the system «the ultrasonic vibrating system - the processed medium» takes place at the stage of the designing of the ultrasonic vibrating system by the choice of type and construction of the ultrasonic vibrating system. The matching in the system «the generator - the ultrasonic vibrating» happens at the stage of tuning of the electronic generator by the compensation of reactive component of the impedance of the ultrasonic vibrating system at its resonance frequency and ignores further possible changes caused by the changes of the mode of operation and also the changes in the vibrating system and the processed medium.(Khmelev, Slivin, Barsukov, Tsyganok, Shalunov, 2010a)

At the changes of the properties of the processed medium the mismatch of the system «the generator - the ultrasonic vibrating system - the processed medium» occurs owing to the changes of acoustic impedance of the processed medium. The presence of the system, which controls the parameters of the processed media, lets increase the efficiency of the enter of the acoustic energy into the processed medium due to the correction of matching elements and maintenance of optimum mode of the operation of the system «the generator - the ultrasonic vibrating system - the processed medium».(Khmelev et al., 2010b)

As the ultrasonic vibrating systems are in contact with the processed medium radiating vibrations into it, the properties of the ultrasonic vibrating system such as the resonance frequency, the mechanical Q, input electrical impedance will depend on the properties of the processed media. Close interconnection of the parameters of the ultrasonic vibrating system and the parameters of the technological media helps to realize the method of indirect control of the parameters of the processed media by the control of the parameters of the ultrasonic vibrating systems. Figure 1 shows the equivalent circuit of the ultrasonic vibrating system (Donskoy, 1982) taking into account the elements caused by the load $\left(\mathrm{R}_{\mathrm{L}} \mathrm{L}_{\mathrm{L}} \mathrm{C}_{\mathrm{L}}\right.$ ). Existing method (Khmelev, Barsukov \& Genne, 2011) lets define the value of the elements of the equivalent electric circuit of the ultrasonic vibrating system.

Pilot experiments on the definition of numeric values of the elements shown in Figure 1, revealed some disadvantages of the measurement procedure (Khmelev et al., 2011), which calculates the values of the parameters of the equivalent electric circuit of the ultrasonic vibrating system with the use of voltage taken from the piezoceramic elements of the ultrasonic vibrating system. In practice this voltage is caused by the reactive components of the matching contour and it differs from the voltage providing current through the load (mechanical branch of the vibrating system).

Figure 2 shows the most common coupling of the piezoelectric transducer to the output stage of the generator.

From the typical coupling of the piezoelectric transducer with the generator (Figure 2) it follows that the voltage on the piezoelements of the ultrasonic vibrating system is caused by the presence of the series-resonant circuit generated by the inductor L and the capacity of the piezoelements. During the operation of the ultrasonic generator the voltage on the $\mathrm{L}$ element equals to the value of the voltage on the piezoceramic elements $\mathrm{Z}$, and it is shifted in phase in $180^{\circ}$. As the voltages on the reactive elements of the electric vibration contour at the resonant frequency fully compensate each other, the current flowing through the vibrating system is caused by the voltage on the secondary transformer winding T (Zernov \& Karpov, 1972). Therefore in the calculations it is necessary to use the supply voltage of the vibration contour, as it is driving force making effective work.

\section{Theory}

Taking into account the remarks mentioned above to calculate the elements of the equivalent circuit of the ultrasonic vibrating system it is necessary to use the following expression:

$$
\mathrm{R}_{0}=\frac{\mathrm{U}_{0}}{\mathrm{I}_{0}} ; \mathrm{L}_{0}=\frac{\mathrm{Q}_{0} \mathrm{U}_{0}}{\omega_{0} \mathrm{I}_{0}} ; \mathrm{C}_{0}=\frac{\mathrm{I}_{0}}{\omega_{0}^{2} \mathrm{Q}_{0} \mathrm{U}_{0}} ;
$$

where $\mathrm{U}_{0}$ and $\mathrm{I}_{0}$ are the voltages at the input of the transformer $\mathrm{T}$ and the mechanical branch current (Abramenko, Khmelev, Barsukov, Shalunov, Genne, 2010) measured during the operation of the ultrasonic vibrating system without loading at the resonance frequency $\omega_{0}$. $\mathrm{Q}_{0}$ is the $\mathrm{Q}$ of the ultrasonic vibrating system without acoustic load (the inherent $Q$ of the ultrasonic vibrating system).

$$
\mathrm{R}_{\mathrm{L}}=\frac{\mathrm{U}_{\mathrm{L}}}{\mathrm{I}_{\mathrm{L}}}-\frac{\mathrm{U}_{0}}{\mathrm{I}_{0}} ; \mathrm{L}_{\mathrm{L}}=\left[\frac{\omega_{\mathrm{L}} \mathrm{I}_{\mathrm{L}}}{\mathrm{Q}_{\mathrm{L}} \mathrm{U}_{\mathrm{L}}}-\frac{\omega_{0} \mathrm{I}_{0}}{\mathrm{Q}_{0} \mathrm{U}_{0}}\right]^{-1} ; \mathrm{C}_{\mathrm{L}}=\frac{\mathrm{I}_{\mathrm{L}}}{\omega_{\mathrm{L}}^{2} \mathrm{Q}_{\mathrm{L}} \mathrm{U}_{\mathrm{L}}}-\frac{\mathrm{I}_{0}}{\omega_{0}^{2} \mathrm{Q}_{0} \mathrm{U}_{0}} ;
$$

where $U_{L}$ and $I_{L}$ are the voltages at the output of the transformer $T$ and the mechanical branch current 
(Abramenko et al., 2010) measured during the operation of the ultrasonic vibrating system in the mode of acoustic loading at the resonance frequency $\omega_{\mathrm{L}}$. $\mathrm{Q}_{\mathrm{L}}$ is the $\mathrm{Q}$ of the ultrasonic vibrating system measured in the mode of acoustic loading.

\section{Practice}

For the experiments the measuring bench, which block diagram is shown in Figure 3, was developed. The measuring bench consists of the ultrasonic generator (the controlled rectifier, the inverter, the matching link and the controlled generator) and the elements of the measuring circuit, which allow to control exciting voltage of LC contour and the mechanical branch current of the ultrasonic vibrating system. The measurements were carried out during the processing of different liquid media at the various levels of the ultrasonic influence.

The generator "Volna" $0.15 / 22$ with the half-wave vibrating system was used as a base of the measuring bench (the radiation area of the working ending is $4 \mathrm{~cm}^{2}$ ).

As processed media engine oil, olive oil, distilled water, ethylene glycol, alcohol and silicone were chosen. The choice of the processed media is caused by different viscosity and cavitation strength, moreover water and alcoholic solutions are the most part of the liquids for the ultrasonic processing.

Each liquid was measured 10 times at the different power levels. On the base of obtained experimental data the values of R, L, C elements of the equivalent circuit of the ultrasonic vibrating system were calculated both without acoustic loading and with acoustic loading. The dependences of these parameters on the current consumed by the ultrasonic vibrating system were received, which in turn were proportionally connected with the mechanical vibration amplitude of the ultrasonic vibrating system.

\section{The results of measurements}

To define the values of the parameters of the equivalent circuit caused by the properties of the vibrating system the number of experiments was carried out in air (the operation under no-load conditions). For applied in the measuring bench ultrasonic vibrating system these parameters are: $\mathrm{R}_{0}=45 \mathrm{Ohm} ; \mathrm{L}_{0}=0.5 \mathrm{H} ; \mathrm{C}_{0}=9.8^{*} 10^{-11} \mathrm{~F}$.

Further the experiments were carried out for each of chosen acoustic loads. The results are presented in the graphs in Figure. 4 - Figure.6.

Figure. 4 shows the dependences of the ohmic resistance of the mechanical branch on the current flowing through the mechanical branch.

It is evident from the graph, that at the small values of the mechanical branch current, when the pre-cavitation mode is realized, ohmic resistance of the mechanical branch for different media varies greatly, that is caused by different physical properties of the processed media. According to the system of electromechanical analogy the active component of impedance corresponds to active loss in the mechanical system. As for acoustic load as a rule this loss is a loss for internal friction of the particles.

With the increase of mechanical branch current (as the cavitation develops in the medium) the active component of the impedance decreases and works to one value, it is caused by the changes in properties of the medium due to the development of the cavitation. The rate of value change of ohmic resistance of the mechanical branch depends on the properties of processed medium, viz on its cavitation strength. The decrease of ohmic resistance (as the cavitation develops in the medium) is caused by the decrease of degree of ultrasonic energy into the medium because of screening of radiating surface of growing cavitation steam and gas cloud.

Figure. 5 and Figure. 6 show the dependences of reactive ( $\mathrm{L}$ and $\mathrm{C}$ ) elements of the mechanical branch of the equivalent circuit of the ultrasonic vibrating system on the current of the mechanical branch.

From the dependences presented in Figure 5 it is clear, that the value of $\mathrm{C}$ element of the equivalent circuit grows, as the mechanical branch current of the ultrasonic vibrating system increases, it can be explained by the changes of reactive (inertial) components of the acoustic impedance of the processed medium.

The rise of inductance value (equivalent to additional mass), as the mechanical branch current is increased (the amplitude of mechanical vibrations), is concerned with enlargement of radiation area of the ultrasonic vibrating system (at low amplitudes the central part of the working tool functions, with the rise of the vibration amplitude peripheral zones start working). Respectively this growth will continue until the radiation area achieves the value of area of the working tool.

Figure. 6 shows the dependences of the capacity of the mechanical branch of the equivalent circuit of the ultrasonic vibrating system on the mechanical branch current. 
According to the system of electromechanical analogy the capacity corresponds to elasticity, but with reference to acoustic load it is more convenient to apply such parameter as velocity of sound in the medium, which is determined by the elasticity and density of the medium.

As the current is increased, the reduction of the value of $\mathrm{C}$ element (the velocity of sound) is observed, it can be explained by the saturation of liquid media with steam and gas cavitation bubbles and approximation of its properties to the ones of gas medium.

\section{Conclusion}

Carried out practical investigations showed the presence of the relation between the physical properties of the processed media and the parameters of the ultrasonic radiators. The presence of such relations let control the properties of the technological media subjected to ultrasonic processing. Controlling the electric parameters of the equivalent circuit of the ultrasonic vibrating system it is possible to control such properties of liquid media as velocity of sound in the processed medium, the value of equivalent additional mass, degree of cavitation development. The integration of such control system into the ultrasonic equipment allows on the one hand to control the processes taking place in liquid media in the ultrasonic fields and on the other hand to optimize the operation of the ultrasonic technological devices.

\section{References}

Abramenko, D.S., Khmelev, V.N., Barsukov, R.V., Shalunov, A.V., \& Genne, D.V. (2010). Way of control of amplitude of ultrasonic influence. Magazine Gauges and systems, 12, 43 - 47.

Donskoy A.V. (1982). Ultrasonic electrotechnological settings. Leningrad: Energoizdat.

Khmelev, V.N., Slivin, A.N., Barsukov, R.V., Tsyganok, S.N., \& Shalunov, A.V. (2010a). Application of ultrasound of high intensity in the industry. Biysk. Altay state technical university, BTI.

Khmelev, V.N., Genne, D.V., Barsukov, R.V., Tsyganok, S.N., Shalunov, A.V., \& Abramenko, D.S. (2010b). The coordination of electronic generators with piezoelectric oscillatory systems for increase of efficiency of ultrasonic devices. News of Tomsk polytechnical university, 4, 139 - 143.

Khmelev, V.N., Barsukov, R.V., Genne, D.V. (2011). Method of indirect control of acoustic load during the operation of the ultrasonic tehnological systems. Polzunovky bulletin, 3,.

Zernov, N.V., \& Karpov, V. G. (1972). Theory of radio engineering circuits, Leningrad: Energy.

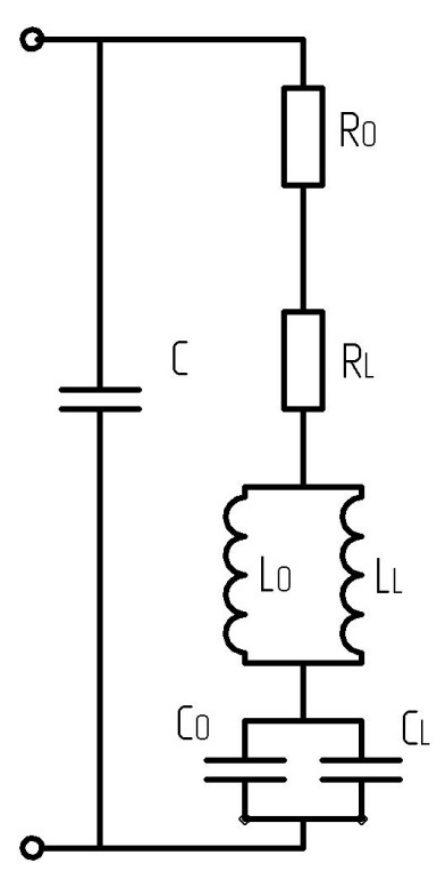

Figure 1. The Equivalent Electric Circuit of The Ultrasonic Vibrating System near the Resonance Frequency 


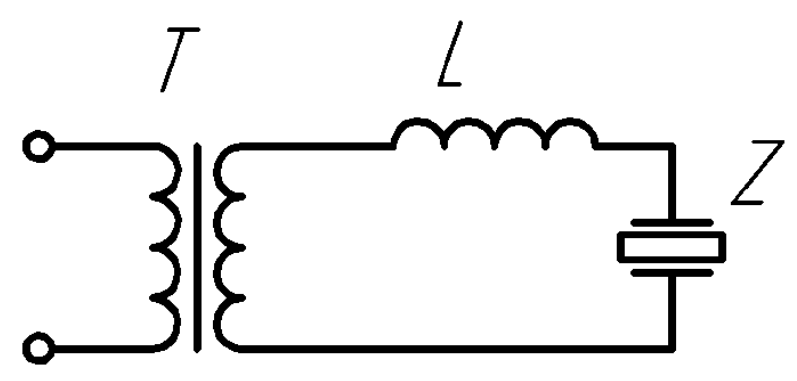

Figure 2. The Coupling of the Piezoelectric Transducer with the Generator

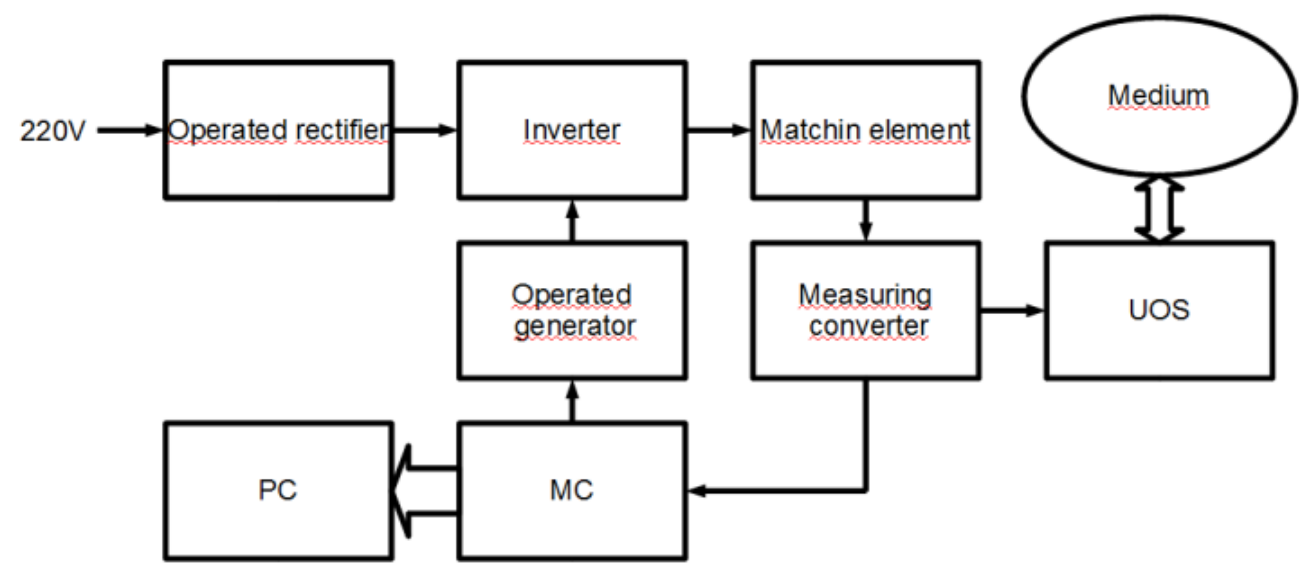

Figure 3. The block diagram of the measuring bench

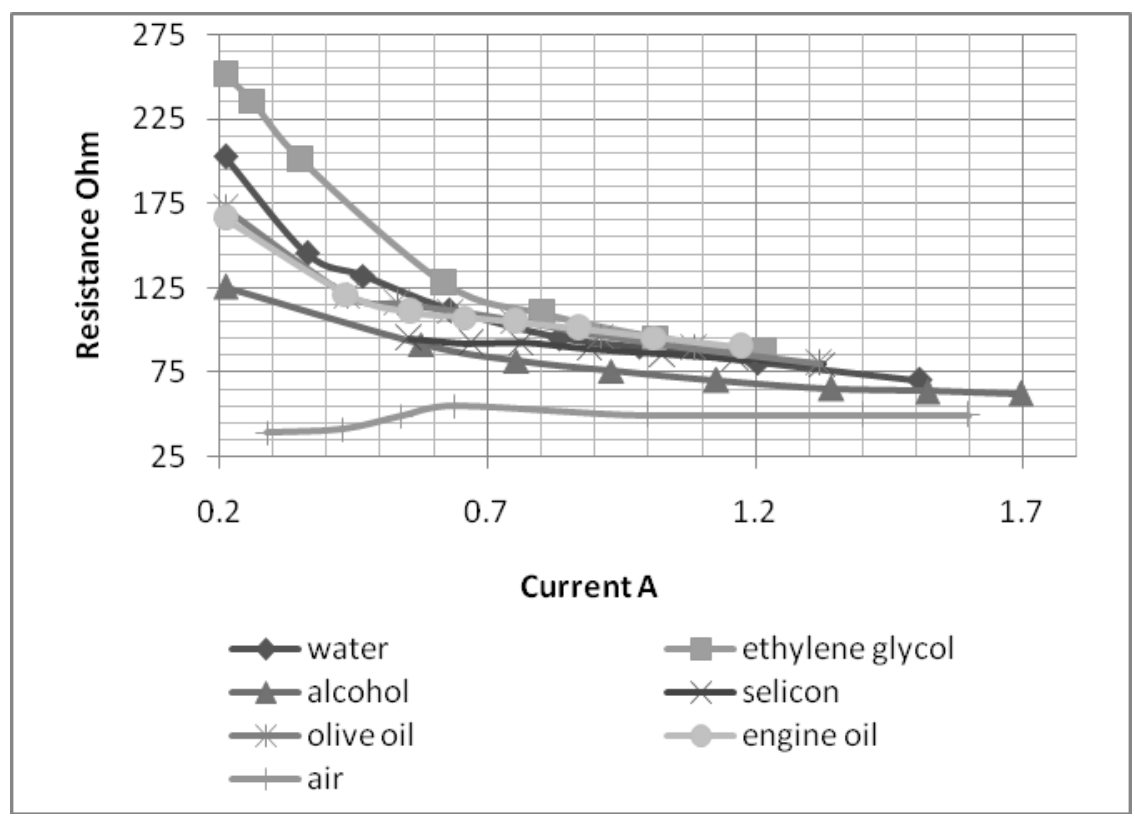

Figure 4. The dependence of the active component of impedance on the current 


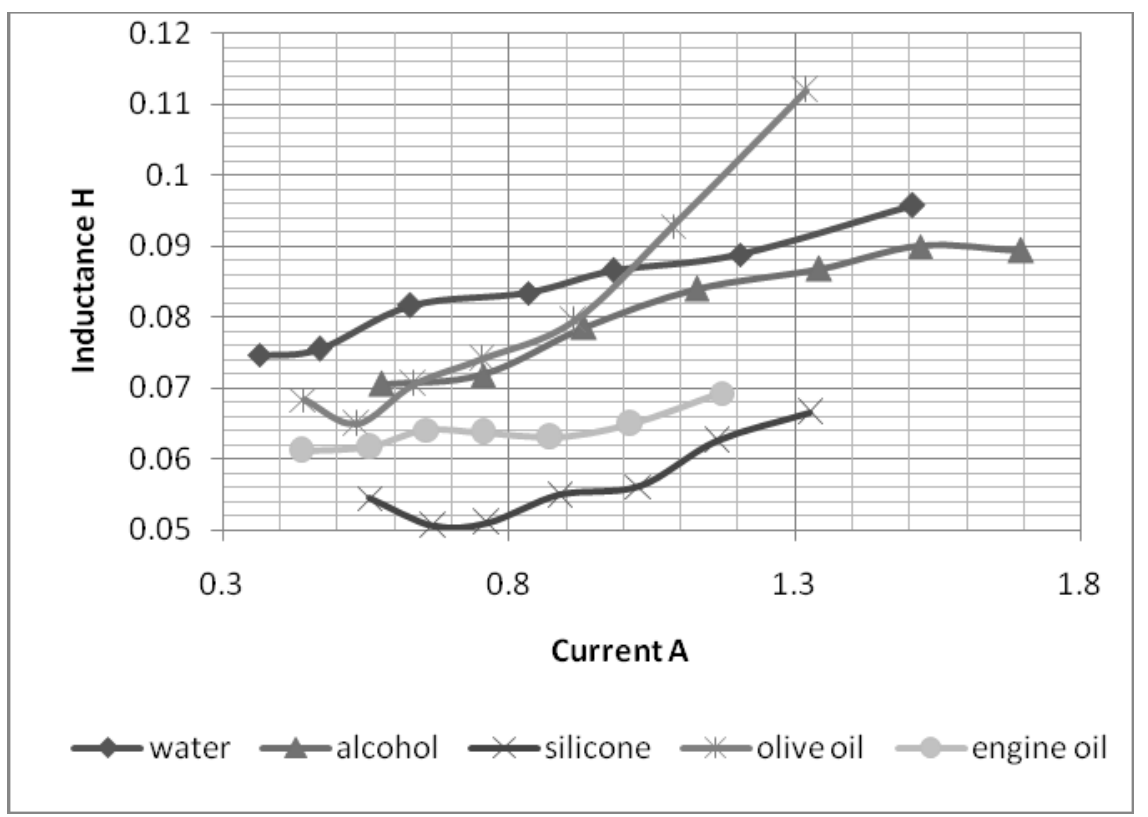

Figure 5. The dependence of the inductance on the mechanical branch current

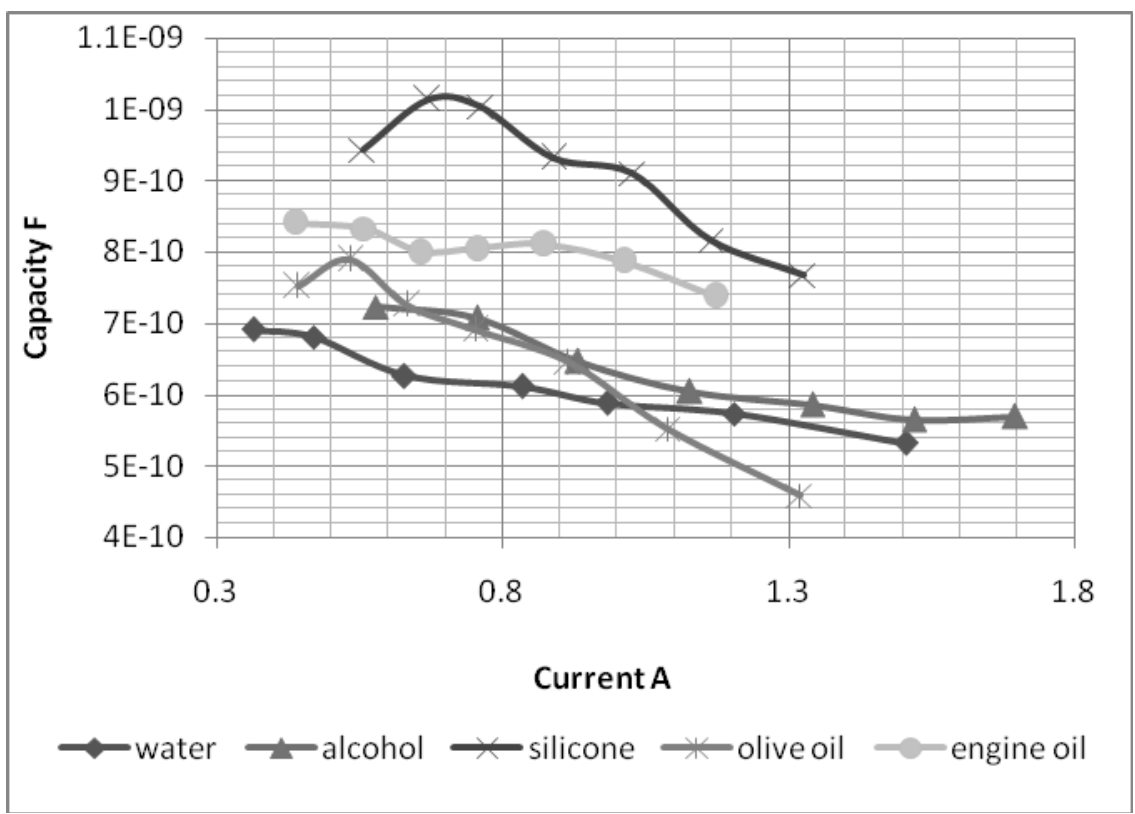

Figure 6. The dependence of the capacity on the current 